\title{
Home Ventilation in Children
}

\author{
Gupta $D^{1}$, Sachdev $A^{2}$, Gupta $N^{3}$, Simalti $A^{4}$
}

\begin{abstract}
Introduction: Home mechanical ventilation (HMV) can prolong survival and improve quality of life. The objectives were to review the challenges, clinical conditions and outcome of children who were discharged from the hospital on respiratory support. Material and Methods: Twenty four patients, who were electively discharged from PICU and had received home ventilatory support for more than 15 days, were enrolled over 11 year study period. Patients were followed up monthly, for two years, for ventilatory requirements, any problems encountered during previous month and for any complication. Results: Twenty four patients with a median age of 3.5 years were discharged home with ventilatory support. HMV was started in 2001 at our hospital. Patents received home ventilation for a median period 5.4 months. Twenty (83.3\%) patients received invasive mechanical ventilation via tracheostomy and four (16.7\%) patients received non-invasive mechanical ventilation. Twelve (50\%) patients received ventilatory support for more than $20 \mathrm{hrs}$ a day and twelve (50\%) patients received only during sleep. On follow up for two years for each patient, twenty (83.3\%) patients successfully came off from ventilatory support while, two $(8.3 \%)$ patients died and two $(8.3 \%)$ lost to followup. Conclusion: $\mathrm{HMV}$ can be safely applied in selected children with CRF after providing adequate training to the care givers. For its more efficient use, we need to have good social support and medical assistance which can be extended to their homes to meet their complete health care needs.
\end{abstract}

Key words: Chronic respiratory failure, Home mechanical ventilation, Ventilatory support.

\section{Introduction}

$\mathrm{M}$ echanical ventilatory assistance is essential for survival in children with respiratory failure. Children who require longterm ventilatory support generally spend a considerable amount of time in hospital, particularly in pediatric intensive care units. It is generally accepted that social, psychological, emotional and developmental needs of children are best met at home ${ }^{1}$. Ventilation at home can be delivered invasively via tracheostomy or noninvasively by either mask intermittent positive or negative-pressure devices ${ }^{2}$. The majority of HMV patients are given ventilatory support in
1Dr. Dhiren Gupta, MD, Senior Consultant, PICU, Sir Ganga Ram Hospital, New Delhi, ²Dr. Anil Sachdev, DMRD, MD, Senior Consultant \& Director, PICU, Sir Ganga Ram Hospital, New Delhi, ${ }^{3}$ Dr. Neeraj Gupta, DCH, DNB, Junior Consultant, PICU, Sir Ganga Ram Hospital, New Delhi, ${ }^{4}$ Dr. Ashish Kumar Simalti, MD, Classified specialist, Military Hospital, Dehradun, Uttarkhand, India.

\section{Address for correspondence:}

Dr. Ashish Simalti

E-mail: ashishsimalti@rediff.com

\section{How to cite}

Gupta D, Sachdev A, Gupta N, Simalti A. Home Ventilation in Children. J Nepal Paediatr Soc 2015;35(1):85-88.

doi: http://dx.doi.org/10.3126/jnps.v35i1.11887

This work is licensed under a Creative Commons Attribution 3.0 License.

\section{(c) (i)}

their homes but some live in public health care institutions or nursing homes. Family members are often involved in daily care and perform technical procedures ${ }^{3}$. These families are assisted by community health care services, especially when the patient is completely dependent on mechanical ventilatory support. A number of studies have investigated the strain put on family caregivers for this patient group, especially the pediatric patient population, but few studies have focused on identifying the challenges of caring for at-home HMV patients using the perspective of community health care services ${ }^{4,5}$. Majority of studies are from west. Data is very scarce from developing countries where most of the hospitals lack in home ventilation facilities. The objective of this study was to 
review the challenges, clinical conditions and outcome of children who are discharged from the hospital on respiratory support, in developing countries.

\section{Material and Methods}

All successive patients who were discharged on mechanical ventilation from 2001 to 2013 at Sir Ganga Ram Hospital (SGRH), New Delhi were evaluated. Patients were analyzed by using a standardized data extraction form which included patient's age, sex, age at which HMV was started, underlying illness, ventilation methods, concurrent use of oxygen therapy, clinical findings and oxygen saturation. Nutritional status was assessed using Z-scores of height and weight. Patients were routinely evaluated every month. Echocardiography for pulmonary hypertension was performed annually. Patients were also interviewed regarding the problems which they experienced during that period.

Initiation of home ventilation: Chronic respiratory failure (CRF) can be defined as the need for mechanical ventilatory support of at least 4 hours per day for a month or longer ${ }^{6}$. In this study, patients with CRF received home ventilation after failure to wean from mechanical ventilation. The primary indication for the use of HMV was chronic alveolar hypoventilation with associated respiratory failure as indicated by hypoxemia and hypercapnia.

Ventilation Method: Patients received either invasive mechanical ventilation via tracheostomy or NIMV (Non-invasive mechanical ventilation) with nasal or full face mask. Settings were adjusted to fulfill the needs of the patients. Children who were to be sent home on ventilator support were selected based on steps described in Table 1. Caregivers were thoroughly trained in using the home ventilatory equipment, aspiration prevention, cardiopulmonary resuscitation, tracheostomy tube care, postural drainage prior to the hospital discharge. Education on the use of the equipment was reinforced during each visit. After discharge patients were visited periodically by technicians of the ventilator company to check their ventilator functionality. Professional nursing was not available for any of the patients but both parents were trained to take care of their child. Routine home care plans, transportation and emergency procedures with a checklist of tips on handling unexpected problems were explained to the parents. The 24 hour emergency helpline telephone numbers were also provided. Patients visited the hospital every 1-3 weekly. Caregivers called the doctor or the technicians of the home ventilator company, when required.

\section{Results}

Out of twenty-four patients, enrolled over 11 years (2001 to 2011), there was no predisposition for either sex noted (Table 2). Children from all age groups (6 months to 14 years) were enrolled with a median of 3.5 years. In our study, younger children clearly outnumbered rest of the group as fourteen (58.3\%) children were less than three years old with only six (25\%) children in between three to six years and four $(16.7 \%)$ were more than six years old.

Patients received home ventilation for a median period of 5.4 months (range: 3 months-12 months). They were classified into three categories of CRF, central control disorders $(n=1)$, chronic lung disease $(n=10)$, and neuromuscular disorder $(n=13)$. All 24 patients were started on home ventilation after the failure to wean from mechanical ventilation.. All patients were ventilated using pressure-controlled ventilation. The median positive inspiratory pressure, positive end-expiratory pressure and respiratory rate were $12 \mathrm{mmHg}$ (range 11-14), $6 \mathrm{mmHg}$ (range4-7) and 15 breaths per minute (range 12-20) respectively. Twenty (83.3\%) patients received invasive mechanical ventilation via tracheostomy. After one month of discharge twelve (50\%) patients received ventilatory support for 20 hours while rest required ventilatory support only during overnight sleep. Four (16.7\%) patients received NIMV. All received NIMV via full face mask and required only during overnight sleep. None of the patients had pulmonary hypertension on evaluation by echocardiography. Equal number (12 each) of patients received nasojejunal and gastrostomy tube feeding. After two years (each child) follow-up, out of 24 patients, 20 (83.3\%) came out from ventilatory support, two $(8.3 \%)$ patient died due to chest infection and septicemia and two (8.3\%) patient lost to follow up. All patients were evaluated monthly.

During first four weeks after discharge, six (25\%) patients had equipment failure which was managed by self inflating ambu bagging but none had hypoxia. Six (25\%) had difficulty in decannulation, of tracheostomy, after successful weaning from ventilators. All ventilators were electricity operated with dedicated invertors as backup.

During home ventilation most of the care was provided by parents. In one case, father was main caregiver and shifted his shop at home. In twenty-two $(91.7 \%)$ cases mothers were main caregivers and more than $50.0 \%$ gave up their job. Eight (33.3\%) parents shifted home near Sir Ganga Ram Hospital. Four (16.7\%) had family discordance and got separated. 
Table 1: Outline of management for long-term mechanical ventilation.

Step 1: Irreversible or slow recovery potential disease was recognized.

Step 2: Parents were adequately trained for using a ventilator care.

Step 3: Ventilator with good home service was chosen.

Step 4: Machine applied in PICU for 1 week.

Step 5: Parents counseled about the needs of the home ventilation.

Step 6: Children were discharge on ventilatory support.

Step 7: Twenty-four hours helpline service was provided.

Table 2: Patient characteristics according to the home ventilation.

\begin{tabular}{|c|c|c|}
\hline \multicolumn{2}{|r|}{ Patient Characteristics } & \multirow{2}{*}{$\begin{array}{c}\text { Number } \\
12\end{array}$} \\
\hline Sov & Male & \\
\hline sex & Female & 12 \\
\hline \multirow{3}{*}{$\begin{array}{l}\text { Underlying } \\
\text { disease }\end{array}$} & Central control disorders & 1 \\
\hline & Chronic lung disease & 10 \\
\hline & Neuromuscular disease & 13 \\
\hline \multirow{2}{*}{$\begin{array}{c}\text { Type of home } \\
\text { ventilation }\end{array}$} & Non invasive mechanical ventilation & 4 \\
\hline & Invasive mechanical ventilation via tracheostomy & 20 \\
\hline \multicolumn{2}{|c|}{ Age at start of HMV (median/years) } & 3.5 years ( 6 months to 14 years) \\
\hline \multicolumn{2}{|c|}{ Duration of HMV (median) months } & 5.4 months (3-12 months) \\
\hline \multirow{2}{*}{ Duration } & Overnight sleep & 12 \\
\hline & 20 hours ventilation & 12 \\
\hline \multirow{2}{*}{ Feeding } & Gastrostomy tube feeding & 12 \\
\hline & Nasoduodenal tube feeding & 12 \\
\hline \multirow{3}{*}{$\begin{array}{l}\text { Complication/ } \\
\text { follow up }\end{array}$} & Pulmonary hypertension & 0 \\
\hline & Lost to follow up & 2 \\
\hline & Death & 2 \\
\hline
\end{tabular}

\section{Discussion}

Our hospital is a tertiary referral hospital. Home ventilator support at this hospital began in 2001 and the number of children treated has increased in recent years (Fig-1). The HMV has been attributed to improved survival rates for critically ill children?.

In this study, we discuss our experience of more than a decade with HMV in patients with CRF. We had very small numbers but high success rate $(>80 \%)$. Invasive mechanical ventilation was required in 83.3 $\%$ patients. Similar study was safely done in $61.1 \%$ patients by Ralph ${ }^{8}$. Patients and caregivers almost invariably prefer non-invasive aids over tracheostomy for safety, convenience, appearance, comfort, facilitating effect on speech, sleep and swallowing and general acceptability ${ }^{9,10,11}$. The use of NIMV in children has increased in recent years. In our study, we managed only four $(16.7 \%)$ children with NIMV. However, Oktem et al studied in $55.9 \%$ patients, where $20.6 \%$ patients died. As it was a large study, we were unable to compare $i^{12}$.
The goal of long-term ventilator support is to correct CRF to allow the child to reach his or her maximum developmental potential and disease reversal. Our data shows that, $75.0 \%$ patients survived and were ventilator free.

This study has demonstrated that a failure of ventilator equipment occurs very infrequently. An analysis of a survey of 150 ventilator-assisted patients over a period of one year found that there was one mechanical failure for every 1.25 years of continuous use and $99 \%$ of ventilator associated problem could be solved at home ${ }^{13}$. In our study, only six (25\%) patients had ventilator failure but they did not suffer from any complications as the parents efficiently resuscitated the children during equipment failure. These families were re-educated to deal with such episodes in time. The childhood CRF can improve with growth, with an improvement of the underlying disease $\mathrm{e}^{14}$. In this study, $83.3 \%$ patients came off ventilator support when their underlying diseases improved. Twelve patients had critical care neuromyopathy, eight had chronic lung disease, and one of each had myopathy, hypoxic 
encephalopathy, acute porphyria and glycogen storage disorder. Two patients were lost to follow up and two died due to chest infection with septicemia. An increase in depressive symptoms and adverse health effects has been reported in mothers and parents who care for medically fragile or chronically ill children at home ${ }^{15,16}$. All of the parents in this study initially worried about the home care.

\section{Conclusion}

Our objectives were to review the challenges, clinical conditions and outcome of children who were discharged from the hospital on respiratory support which we have described and we can say that ventilation can be safely applied in selected children with CRF with close monitoring and proper follow-up, despite the lack of professional home care nurses or respiratory therapists.

Acknowledgements: Nil

Funding: Nil

Conflict of Interest: None

Permission from IRB: Yes

\section{References}

1. Hewitt-taylor J: children who require longterm ventilation: staff education and training. Intensive Crit Care Nurs 2004;20:93-102.

2. Simonds AK. Home ventilation. Eur Respir J 2003;22:38-46.

3. Kirk S, Glendinning C: Supporting 'expert' parents-professional support and families caring for a child with complex health care needs in the community. Int J Nurs Stud 2002; 39:625-35.

4. O'Donohue WJ, Giovannoni RM, Goldberg Al, et al: Long-term mechanical ventilation:guidelines for management in the home and at alternate community sites: report of the adhoc committee, Respiratory Care section, American College of Chest physicians. Chest 1986;90:1-37.

5. Dybwik K, Nielsen EW, Brinchmann BS. Home mechanical ventilation and specialised health care in the community: Between a rock and a hard place. BMC Health Serv Res 2011; 11:115.

6. Hammer J. Home mechanical ventilation in children: indication and practical aspects. Schweiz Med Wochenschr 2000;130:1894-902.

7. Keens TG, Jansen MT, DeWitt PK, et al: Home care for children with chronic respiratory failure. Semin Respir Med 1990;11:269-81.

8. Ralph C, Frates Jr, Mark LS et al. Outcome of home mechanical ventilation in children. J Pediatr 1985;106:850-56.

9. Kremer B, Botos-Kremer Al, Eckel HE,Schlondorff G: indications, complications, and surgical techniques for pediatric tracheostomies - an update. J Pediatr Surg 2002;37:1556-562.

10. Hoskote A, Cohen G, Goldman A, Shekerdemian $\mathrm{L}$ : Tracheostomy in infants and children after cardiothoracic surgery: indications, associated risk factors, and timing. J Thorac Cardiovasc Surg 2005;130:1086-93.

11. Bahng SC, VanHala S, Nelson VS, Hurvitz EA, Roloff DW, Grady EA, Lewis CC: Parental report of pediatric tracheostomy care. Arch Phys Med Rehabil 1998; 79: 1367-1369.

12. Oktem S, Ersu R, Uyan ZS, et al. Home ventilation for children with chronic respiratory failure in Istanbul. Respiration 2008;76:76-81.

13. Heckmatt JZ, Loh L, Dubowitz V. Night-time nasal ventilation in neuromuscular disease. Lancet 1990;335:579-82.

14. Fauroux B, Sardet A, Foret D: Home treatment for chronic respiratory failure in children: a prospective study. Eur Respir J 1995;8:2062-66.

15. Patterson JM, Leonard BJ, Titus JC: Home for medically fragile children: impact on family health and well-being. J Dev Behav Pediatr 1992;13:24855.

16. Tsara V, Serasli E, Voutsas, Lazarides V, Christaki P: Burden and coping strategies in families of patients under noninvasive home mechanical ventilation. Respiration 2006;73;61-67. 